\title{
RAZŌES PARA O DECLÍNIO DA RETÓRICA MUSICAL NO SÉCULO XIX
}

\begin{abstract}
William Teixeira da Silva*
Silvio Ferraz

RESUMO: O trabalho discute os eventos que levaram a retórica, dispositivo essencial para a estruturação da linguagem musical, a não mais ser utilizada e estudada dentro da prática musical. A discussão visa identificar as razões pelas quais tal declínio ocorreu, principalmente através das modificações no pensamento filosófico, que se refletiram na construção da arte musical como um todo. Por fim, serão identificados alguns pontos remanescentes nos quais pode ainda ser visto o espírito da retórica na música posterior.
\end{abstract}

PALAVRAS-CHAVE: Retórica musical, Descartes, Hanslick, Wagner, Perelman

\section{REASONS FOR DECLINE OF MUSICAL RHETORIC IN THE NINETEENTH CENTURY}

ABSTRACT: This paper discusses the events that led rhetoric, an essential device to the structuring of musical language, no more being used and studied inside the musical practice. The discussion aims to identify the reasons for this decline occurred primarily through changes in philosophical thought, which is reflected in the conception of music at all. After that, we will look for traces of rhetoric in the music later.

KEYWORDS: Musical Rhetoric, Descartes, Hanslick, Wagner, Perelman

\section{INTRODUÇÃO}

É ponto pacífico e objeto de estudo bastante pesquisado a influencia da arte retórica na estruturação de uma linguagem
*UNICAMP -

teixeiradasilva.william@ gmail.com

Auxílio FAPESP

**UNICAMP -

silvioferrazmello@gmail.com 
1. i. e. BARTEL, $1997 \mathrm{e}$ TARLING, 2004. própria para a música instrumental ${ }^{1}$. Essa relação, que tem sido cada vez mais afirmada como inata às linguagens verbal e musical, sem dúvida atingiu seu ápice nas obras de compositores e tratadistas do período barroco.

Todavia, a partir do final do classicismo, a música passou a se dirigir para novos rumos e a retórica não mais atenderia a essas demandas, sendo pouco a pouco deixada de lado. Mas será que foram apenas a música e seus, até então, artífices que se afastaram tão veementemente do estudo da retórica? E por que tal distanciamento teria ocorrido? E mais, seria válida a tentativa de compreender se essa influencia morfológica ainda persiste na música que nos é contemporânea?

\section{Metodologia}

Em vista de indicadores que permitam uma compreensão deste declínio da retórica no discurso musical, o estudo tem início ao avaliar a própria noção de retórica tida a partir do século XIX. Desse modo, o grau de objetividade é ampliado pelo alinhamento deste pensamento a epistemologias coerentes à discussão e válidas na atualidade desses estudos, possibilitando o distanciamento de um caráter evolutivo que ainda tende a existir em visões sobre o desenvolvimento histórico de qualquer dispositivo como o objeto em questão.

Essa é a razão pela qual o principal referencial teórico que embasa a discussão é o Tratado da Argumentação: a Nova Retórica, de Chaïm Perelman e Lucie Olbrechts-Tyteca, de 1958 e editado em língua portuguesa em 1996. Esse livro é um marco inicial para o estudo da retórica no século XX, pois fez o alinhamento mencionado entre retórica clássica e a filosofia contemporânea, não só considerando os postulados aristotélicos, mas, em determinados pontos, os revendo e os ampliando. A partir dessa obra será viável proceder a análise crítica da produção musical, epistolar e literária feita durante o século XIX, momento em que estamos localizando uma mudança nos paradigmas de compreensão da música, ou mesmo das artes. 
A arte retórica, como foi registrada por Aristóteles no séc IV a. C e disseminada em obras como a Retórica e os Tópicos, trilhou um longo caminho através dos séculos desde sua sistematização. Até que seu estudo fosse atualizado por Quintiliano na Institutio Oratoria, muitos outros estruturaram seu pensamento com o conjunto de conhecimentos nela contido. Sem que tenha tido momento algum de aceitação unânime, foi combatida ainda na Grécia Antiga (como exemplo, por Górgias), sendo seu estudo implementado e estendido sem maiores complicações até o advento do pensamento Iluminista. A partir de então, desde sua estrutura epistemológica até sua utilização, seus componentes passaram a ser amplamente questionados, resultando, enfim, em sua deslegitimação enquanto conhecimento, sendo relegada a um ostracismo bastante duradouro.

No final do século XVII, pode ser pontuado como um dos primeiros ataques mais veementes aqueles perpetrados pelo filósofo francês René Descartes (1596-1650). Apesar de ter desenvolvido seu trabalho, sua obra só encontrou aplicabilidade mais plena através das reformas no pensamento e, sobretudo para a música, na educação, através dos adeptos do Romantismo.

Para Descartes, a retórica, enquanto ferramenta de síntese das provas dialéticas ${ }^{2}$ e, portanto, apenas verossímeis, não continha valor algum, senão um possível pendor estético. Sendo a evidência, a prova analítica, a marca da razão, somente dispositivos que operam em silogismos fechados são passíveis de uso. A música, possuindo propriedades estruturais e semânticas que a retórica lhe proporcionou, jamais seria capaz de atender essa demanda operacional dentro de uma linguagem essencialmente apodítica. Desse modo, a mudança de paradigma da "arte" para a "ciência" impediu que a retórica possuísse lugar nesse sistema, como fica claro na afirmação a seguir:

Todas as vezes que dois homens formulam sobre a mesma coisa um juízo contrário, é certo que um dos dois se engana. Há mais, nenhum deles possui a verdade; pois se um tivesse dela uma visão clara e nítida poderia expô-la a seu adversário, de tal modo que ela acabaria por forçar sua convicção. (DESCARTES apud. PERELMAN; OLBRECHTS-TYTECA, 1996: p. 2).
2. Define-se dialética, aqui, dentro da concepção aristotélica do termo: "Ora, uma proposição dialética consiste em perguntar alguma coisa que é admitida por todos os homens, pela maioria deles ou pelos filósofos, isto é, ou por todos, ou pela maioria, ou pelos mais eminentes, contanto que não seja contrária à opinião geral; pois um homem assentirá provavelmente ao ponto de vista dos filósofos se este não contrariar as opiniōes da maioria das pessoas. As proposições dialéticas também incluem opiniões que são semelhantes às geralmente aceitas; e também proposiçōes que contradizem os contrários das opiniōes que se consideram geralmente aceitas, assim como todas as opinióes que estão em harmonia com as artes acreditadas." (ARISTÓTELES, 2000, p. 15). 
É redundante dizer que todo o trabalho de desenvolvimento do material musical através de procedimentos oriundos da retórica tornou-se invalidado nesse panorama, pois, o que pode ser argumentado, ou em música, variado e resultar no objetivo aqui definido? Essa propriedade coerciva que a lógica continha na acepção cartesiana, de fato, tornava inútil qualquer discurso que visasse à argumentação. A nova contingência levou a música a dois rumos opostos e, ambos, distantes da concepção original de retórica. Partindo da contribuição do próprio Descartes para a compreensão sobre as paixões e sua força sobre os espíritos foram feitas tentativas de conciliação dentro do paradoxo criado.

O primeiro rumo foi atribuir significados e estados emocionais que deveriam ser compreendidos na escuta da música e justificariam a relevância da música enquanto linguagem, mesmo que sem logos, mas com capacidade única de manipulação e classificação do pathos. A segunda maneira de superar o problema imposto foi, indo a rumo oposto, a aceitação da total incapacidade da música em ter um discurso adequado a esse nível de racionalidade. Sendo assim, bastaria a ela lidar com seus próprios recursos, por fim, integralmente estéticos.

Perelman e Olbrechts-Tyteca avaliam de maneira bastante trágica os caminhos da racionalidade humana que aqui começaram a varrer para compartimentos distantes o saber que não se enquadrava na nova doutrina e que culminaram na lógica formal, a autodeclarada onipotência da ciência:

Deveríamos, então, tirar dessa evolução da lógica e dos incontestáveis progressos por ela realizados a conclusão de que a razão é totalmente incompetente nos campos que escapam ao cálculo e de que, onde nem a experiência, nem a dedução lógica pode fornecer-nos a solução de um problema, só nos resta abandonarmo-nos às forças irracionais, aos nossos instintos, à sugestấo ou à violência? (PERELMAN; OLBRECHTS-TYTECA, 1996: p. 3).

Junto a esse pensamento cientificista veio a contribuir o filósofo Georg Friedrich Hegel, sobretudo na Enciclopédia das Ciências Filosóficas. Sua contribuição age em duas frentes, tanto no âmbito lógico, com sua redefinição do pensamento dialético, ao qual ele conferiu uma nova ordem dos termos, privilegiando a lógica indutiva. Esse foi mais um ponto negativo atribuido ao pensamento aristotélico e, com isso, à retó- 
rica. Além disso, Hegel produziu na própria área da estética, constantemente utilizando a música como objeto de análise e conferindo maior valor a ela devido a seu nível de abstração frente às outras artes, fazendo parecer possível a busca por uma expressão universal, desde que a linguagem operasse dentro de si mesma.

Com o descrédito no qual a retórica se encontrava em meados do século, seu ensino foi cada vez mais reduzido, lentamente desaparecendo como disciplina elementar até o século $\mathrm{XX}$, como fica evidente no raro excerto de seu estudo:

Com efeito, o assunto [a retórica] talvez esteja apenas alguns graus acima da Lógica na estima popular; sendo uma em geral considerada pelo vulgo a arte de desnortear os cientistas com sutilezas frívolas; a outra, a de enganar a multidão com mentiras especiosas. (WHATELY, 1861: v-vi).

Esse foi o golpe mais duro que a retórica sofrera desde sua primeira sistematização, pois com a eliminação do estudo da disciplina, sua própria definição sofreu grandes distorçôes, afetando a concepção que todos, especialmente os músicos, tinham de suas possibilidades e importância. Grande parte dos problemas e conflitos que decorreram desses eventos foram ocasionados devido à rígida divisão de disciplinas que alienou da formação do homem aspectos fundamentais da estruturação lógica do pensamento e que se desdobraram no modo como a música passou a ser produzida. Isso, enfim, abriu o espaço deixado pela retórica para os novos ideais românticos de expressão artística.

Vitor Hugo, literato romântico, rejeita a retórica opondo-lhe o paradigma de um ideal de sinceridade, que consistiria no uso espontâneo da linguagem. O Positivismo, por seu turno, exclui de seu ideal de construção de uma ciência da linguagem todo um conjunto de elementos valorativos e emotivos, até então consagrados na tradição das técnicas retóricas. (MAZZALI, 2008, p. 10).

\section{A MÚSICA SEM LOGOS}

Dentro desse conflituoso panorama construído em torno da retórica, os mecanismos que constituiriam a linguagem musical não poderiam permanecer inalterados. Da mesma ma- 
neira que o Idealismo e o Positivismo, cada um a seu modo, tentaram oferecer soluções para as problemáticas levantadas por pensadores Iluministas, a música reagiu a essas mudanças com alterações bastante radicais em todos os seus elementos.

Mesmo com cada região da Europa possuindo sua nuance quanto ao grau e acepção de retoricidade na música, a Alemanha que vira acontecer grandes avanços na retórica musical, de Mattheson a Walther (primo de J. S. Bach), também abrigou discussões muito ricas, como as que envolveram os ideais de Richard Wagner e de Eduard Hanslick, que, por vezes, pode ser lido como um porta-voz da estética pretendida por Johannes Brahms.

No concernente à retórica, ela ainda estava presente nas peças de ambos, todavia, proporcionando o desafio ao público de hoje em entender de que tipo de retórica cada um está falando.

Nessa carta comentando a tradução de Tannhäuser para uma apresentação na França, Wagner concede à retórica uma importância aparentemente enorme.

Considero lamentável o estado da arte francesa neste momento; essa poesia [Tannhäuser] é algo totalmente estranho a essa nação, e, no seu lugar, ficam apenas a retórica e as frases sonoras. Com a língua francesa completamente centrada em si mesma e sua resultante incapacibilidade de assumir o controle do elemento poético que falta às outras línguas, o único método restante é deixar a poesia influenciar o francês através da música. (...) Gluck só ensinou aos franceses como levar música à harmonia com o estilo retórico da tragédia francesa. Não estamos preocupados com a poesia de verdade no caso dele de forma alguma. Essa é a razão pela qual, desde então, os italianos se ocuparam desse campo quase exclusivamente, já que a questão sempre foi o método retórico de expressão em vez da música em si, muito menos da poesia (...). (KOBBE, 1905, p. 211-212).

Atendendo aos caminhos idealistas para uma linguagem musical, Wagner se valeu de sua visão da retórica para construir um léxico próprio de figuras, posteriormente chamadas de leitmotiven, que possibilitariam ao mesmo tempo a total abstração e a própria ressignificação da relação palavra/música, culminando com a construção de uma linguagem suprema e universal. Esse tipo de discurso demanda o que Perelman chamará de "auditório universal" ${ }^{3}$, um tipo de auditório ho- 
mogêneo, o que no caso da música corresponderia a um tipo de ouvinte homogêneo, que estaria submisso à força coerciva do argumento acima exposto, mas que, em última instância, habita unicamente o mundo da suposição.

Dentro do âmbito real do discurso, é necessária a constante negociação por conexões de significação para que se estabeleça alguma relação argumentativa. "ao auditório que cabe o papel principal para determinar a qualidade da argumentação e o comportamento dos oradores" (PERELMAN; OLBRECHTS-TYTECA, 1996, p. 27), ou seja, é em função do auditório que se desenvolve o discurso.

Por outro lado, se opôs diametralmente a Wagner e seus ideais estéticos o crítico musical Eduard Hanslick. A contribuição de Hanslick, entre outras, para o desaparecimento da Doutrina dos Afetos foi precisa e ainda permanece relevante em alguns aspectos. Sua busca era incessante por uma linguagem musical desprovida de qualquer vínculo de representatividade ou de funcionalidade. No trecho a seguir, Hanslick fala da ineficácia da relação retórica entre palavra e música em Bach.

De outros numerosos exemplos em J. S. Bach lembremos apenas todas as peças em forma de madrigal no Oratório de Natal, que, como se sabe, são retiradas sem maldade de diversas canções profanas de ocasião. (HANSLICK, 1989, p. 49).

Aqui, o crítico oferece um belo exemplo da diferença entre prosódia e retórica, mas não a falha da última. Ao se limitar ao mero alinhamento entre a linha melódica e o texto verbal, Hanslick parece não levar em conta o lugar-comum escolhido por Bach na etapa da inventio de sua composição, exatamente como costumava ser prescrito pelo reformador Martinho Lutero, de modo a facilitar e aproximar o entendimento da congregação. Reduzir a retórica musical apenas a relação de significâncias foi uma asserção bastante leviana à totalidade de sua presença na música

Cometendo outro equivoco trivial aos olhos do Aristóteles da Retórica, Hanslick desvencilha, em seu livro, os três âmbitos primordiais, ethos, pathos e logos, que sustentam a relação tripartida orador x discurso x auditório ${ }^{4}$. Apesar da música dever a Descartes boa parte de sua concepção moderna de Afeto $^{5}$, toda a possibilidade de um discurso equilibrado nos

\author{
3. PERELMAN; \\ OLBRECHTS-TYTECA, \\ 1996, p. 34.
}


4. MOSCA, 2001, p. 22

5. DESCARTES, 1973. âmbitos ético, patético e lógico, ruiu diante das proposições do filósofo a respeito da retórica.

Ao identificar a leitura fragmentada da retórica musical que circulava em diversas variações pelas mentes de críticos e músicos, se torna mais claro a passagem que era feita, no estudo do repertório antigo, de uma utilização retórica para um tão-somente procedimento composicional. É o que acontece no exemplo a seguir: Bach efetua um processo de variação oriundo da argumentação, onde os contrapontos XII e XIII, da Arte da Fuga, funcionam como peroratio, verticalizando processos contrapontísticos (confirmatio) já efetuados em relação ao sujeito (propositio). De todo esse contexto ricamente retórico, Brahms retirou apenas o desenvolvimento temático apresentando o tema com um contraponto similar na parte do piano.

Contrapunctus $[13$,$] a 3. (rectus et) inversus. { }^{*}$ (rectus.)

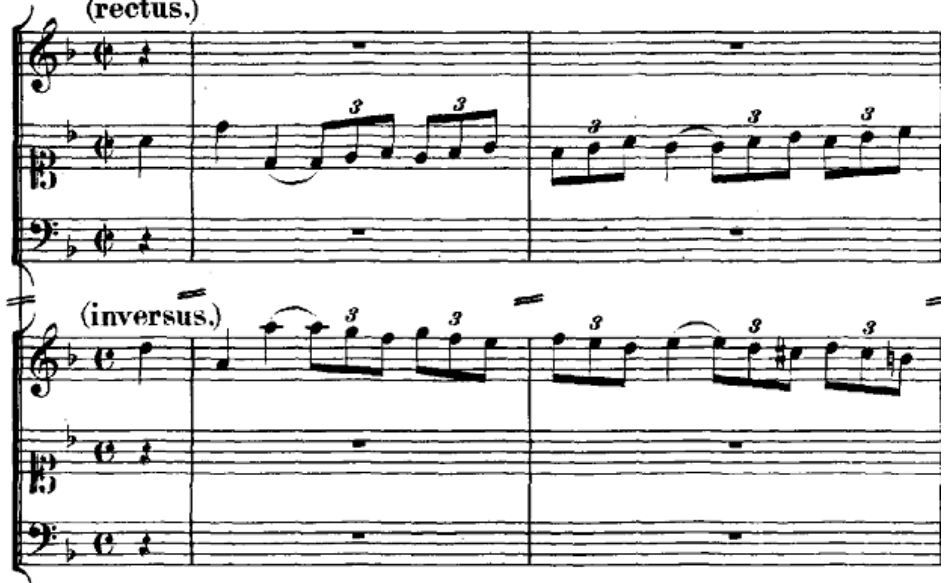

Figura 1: Bach, J. S. A arte da fuga: contraponto 13, cc.1-2

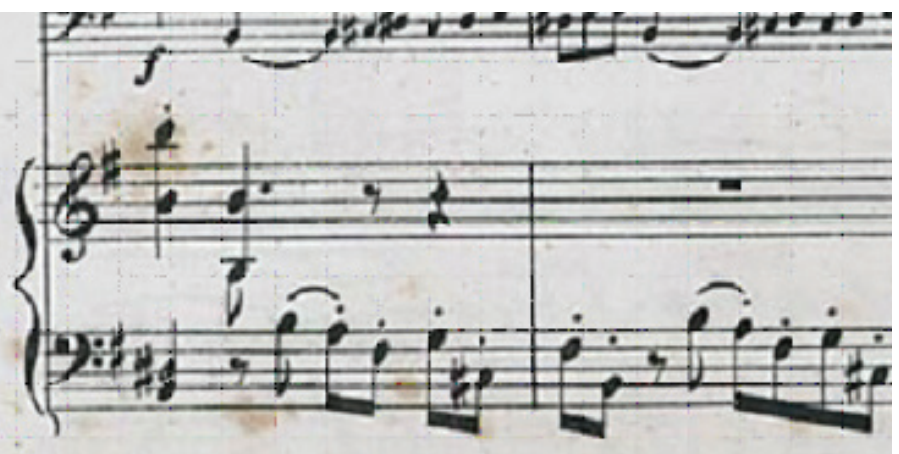

Figura 2: Brahms, J. Sonata para violoncelo e piano em Mi menor opus 38: 3o movimento: cc. 5-6 
Reconhece-se, entretanto, a legitimidade da crítica de Hanslick aos excessos quase dogmáticos cometidos por praticantes da retórica musical. Por mais correta que tenha sido a associação entre Afeto e propositio, já que não se nega os frutos musicais desse tipo de pensamento, a prática desse conceito pouco pôde ser aproveitada fora de certos níveis de compreensão circunscritos a determinados grupos sociais. Isso não diminui de forma alguma o valor da ideia, muito menos o da música, mas o fato é que não era essa a intenção dos tratadistas que visavam a elaboração de uma linguagem mais próxima do universal, como posteriormente tentou também Wagner. Sem dúvida, foi aqui que um equívoco de compreensão da retórica clássica contribui para o enfraquecimento desse pensamento. Não considerando a entidade retórica do Auditório, sobrecarregou-se com um nível demasiado grande de representações a linguagem musical, não estando o público apto a compreender a totalidade pretendida, já que a própria formação do indivíduo estava sendo modificada, além, é claro, da evidente e crescente heterogeneidade dentre os inúmeros tipos de pensamento, mesmo se nos limitarmos a aristocracias européias.

A grande contribuição da Nova Retórica, que é a ênfase na entidade receptora do discurso, o Auditório, é um elemento mais discreto na retórica clássica, mas ainda sim existente. A omissão desse fator nas críticas, como as direcionadas a J. S. Bach e a Richard Wagner, reduz a música a impossível para qualquer criação humana, ainda mais musical.

Embora não se discuta que uma tribo indígena dificilmente irá compreender o crucifixo bachiano ou o leitmotif de Parsifal, seria ilegítimo retirar essa carga semântica da leitura de obras do tipo, pois elas trazem em si condiçôes de serem entendidas, mesmo que por um público muito específico. Não é porque hoje cada uma dessas peças carece de vínculo de significância com o público, que se torna válido ignorar essa propriedade que, seja por alunos do Colégio de São Tomás, em Leipzig, ou pelos espectadores do Auditório do Festival, em Bayreuth, um dia já pôde ser de fato assimilada.

Por mais efetivo que determinado trabalho seja, é impossível garantir a integralidade da obtenção do resultado pretendido por seu autor. Porém, a não obtenção dessa integralidade não corresponde a uma ineficácia da obra da arte, do ensino, enfim, de um discurso. Isso deve nos levar, sim, a uma outra 
visão da objetividade, que é própria da retórica e se refere não à expectativa do que será necessariamente, mas do que será possivelmente alterado no auditório.

No meio dessa controvérsia, a perda da referencialidade levou muitos que não queriam lidar com uma música autônoma a recorrerem a recursos externos para garantir a continuidade de sua música, como foi o caso da música programática, que do extra-musical derivava a disposição de todo o material. Mesmo contendo em si modificações bastante acentuadas da concepção aristotélica, o pensamento dialético, então na acepção hegeliana do termo, foi um importante instrumento de manutenção da retórica dentro da música, por mais apagado que pareça ser esse vestígio. Sendo a dialética justamente onde a retórica foi concebida, por motivos outros, ela teve seu processo de organização trazido à tona e valorizado frente a outros aspectos discursivos, mas, ainda sim, mantendo-se longe dos demais recursos criativos, organizacionais e expressivos que pouco antes a música havia apreendido da retórica, todavia, presente como procedimento diante das novas linguagens pós-tonais 6 .

A retórica é a outra face da dialética; pois ambas se ocupam de questōes mais ou menos ligadas ao conhecimento comum e não correspondem a nenhuma ciência particular. De fato, todas as pessoas de alguma maneira participam de uma e de outra, pois todas elas tentam em certa medida questionar e sustentar um argumento, defender-se ou acusar. (ARISTÓTELES, 2005, p. 89).

\section{CONSIDERAÇŌES FINAIS}

Com o exposto pretendeu-se mostrar que, além de outros, o problema mais crítico para a retórica no século XIX foi o desconhecimento de sua própria definição e constituição, ocasionado pelo declínio de seu estudo frente às novas tendências filosóficas. Contudo, acima de minúcias e equívocos conceituais está o fato de que ambas as soluções românticas foram válidas a seu modo. A forma como esses procedimentos ainda persuadem a audição, mesmo não se utilizando conscientemente do arcabouço retórico, é o que tem suscitado questionamentos e justificado a procura por vestígios da retórica até a música atual, já que "todo discurso é uma construção retórica, 
na medida em que procura conduzir o seu destinatário na direção de uma determinada perspectiva do assunto" (MOSCA, 2001, p. 23).

A análise evidencia que o período marcou a dissociação do conceito clássico daquele efetivamente praticado na música, todavia resguardando elementos diretamente derivados da retórica musical, sobretudo os processos figurativos e gestuais, além, é claro, da própria estrutura formal, que de uma maneira geral se emancipou do contexto maior que a justificava. Auxilia no entendimento cronológico dos eventos o fato de que houve uma ruptura no estudo da disciplina e quanto mais afastado se esteve do ensino formal, mas dispares passaram a ser as atribuições a ela conferidas, resultando em um gradual esquecimento de seu papel nas origens da escrita musical.

A compreensão das razóes desse declínio estabelece um campo que possibilita sua transposição para a realidade atual. Seria do interesse da música, hoje, estabelecer alguma espécie de vínculo com o auditório? Se sim, poderia o estudo da retórica otimizar essa relação como o fez na música renascentista e barroca? Essas questões, por ora abertas, no mínimo possibilitam a reflexão sobre o modo como o discurso, inclusive o musical, pode ser alterado e influenciado ao mediar a relação entre a entidade produtora e a entidade receptora.

Prossegue-se, através do mesmo método, a pesquisa por traços da retórica no pensamento e, por conseguinte, na música do século XX, onde os processos dialógicos mantiveram alguma herança retórica, junto a alguns que ainda concebiam a música figurativamente, até finalmente chegar à música contemporânea, objeto central dessa pesquisa. A preocupação com a coerência conceitual conduzirá a proveniente reflexão sobre a possibilidade de se falar em uma retórica dentro da música contemporânea.

REFERÊNCIAS BIBLIOGRÁFICAS

ARISTÓTELES. Retórica. 2a ed. Revista. Lisboa: Imprensa Nacional, 2005.

Tópicos. Lisboa : Imprensa Nacional, 2005. 
BARTEL, Dietrich. Musica poetica: musical rhetorical figures in German Baroque music. Lincoln: University of Nebraska Press, 1997

BUELOW, George. Rhetoric and Music. In: The New Grove Dictionary of Music and Musicians, ed. Stanley Sadie (London: Macmillan, 1980), 15:793.

DESCARTES, René. As Paixões da Alma. Coleção Os Pensadores. 1a Ed. Tradução: J. Guinsburg e Bento Prado Júnior. São Paulo: Abril Cultural, 1973.

FUBINI, Enrico. Estética da Música. Lisboa: Ediçōes 70, 2003.

GREENBAUM, Mathew. Debussy, Wolpe and Dialectical Form. In: Contemporary Music Review: Stefan Wolpe Issue (Spring 2008).

HANSLICK, Eduard. O Belo Musical: uma contribuição para a revisão da estética musical. Tradução de Nicolino Simone Neto. Campinas: Editora d+a UNICAMP, 1989.

KOBBE, Gustav. Wagner and his Isolde. New York: Dodd, Mead \& Company, 1905.

MAZZALI, Gisele Cristina. Retórica: de Aristóteles a Perelman. Revista Direitos Fundamentais \& Democracia. v. 4, 16p., 2008.

MAZZOTTI, Túlio Bonilha. A virada retórica. Educação \& Cultura Contemporânea. Rio de Janeiro, v. 4, n. 8, p. 77-104, $2^{\circ}$ semestre de 2007.

MOSCA, Lineide Salvador. Velhas e novas retóricas: convergências e desdobramentos. In: Retórica de ontem e hoje. São Paulo: Editora Humanitás, 2001.

PERELMAN, Chaïm, OLBRECHTS-TYTECA, Lucie. Tratado da argumentação: a nova retórica. Tradução Maria Ermantina Galvão G. Pereira. São Paulo: Martins Fontes, 1996. 
SILVA, William Teixeira da. Relaçôes entre a retórica aristotélica e a Nova Retórica e sua aplicação em Música. Trabalho de Conclusão de Curso: UNESP/São Paulo, 2012.

TARLING, Judy. The Weapons of Rhetoric: a guide for musicians and audiences. Hertfordshire: Corda Music, 2004.

WHATELY, Richard. Elements of Rhetoric. Nashville: Southern Methodist Publishing House, 1861.

WILLIAMS, Peter. Figurenlehren from Monteverdi to Wagner. 1: What is 'Figurenlehre'?, The Musical Times, Vol. 120, No. 1636 (Jun., 1979) p.476-479. 